\title{
Solution for Infusion Dosage Form
}

National Cancer Institute

\section{Source}

National Cancer Institute. Solution for Infusion Dosage Form. NCI Thesaurus. Code C149910.

Liquid sterile preparation consisting of an aqueous solution intended to be introduced, usually in large volumes, usually into the circulating blood stream. 